\title{
THE INFLUENCE OF THE ANGLE OF THE WORKING PART OF THE DIE ON THE HIGH SPEED DRAWING PROCESS OF LOW CARBON STEEL WIRES
}

\begin{abstract}
The paper contains the theoretical and experimental analysis of the impact of the drawing angle on the drawing process and the properties of low carbon steel wires. A multi-stage drawing wire rod with a diameter of $5.5 \mathrm{~mm}$ on a wire with a diameter of $1.0 \mathrm{~mm}$ has been carried out in two stages. The first one consisted of preliminary drawing wire rod for the wire with a diameter of $2.2 \mathrm{~mm}$ which was next subjected to the drawing process at a speed of $25 \mathrm{~m} / \mathrm{sec}$ at the final wire with a diameter of $1.0 \mathrm{~mm}$. The wires were drawn in conventional dies with drawing angle $\alpha=3,4,5,6,7$ degrees.

For the wires drawn in respective variants, the investigation of the mechanical properties was performed and the amount of lubricant on the surface of steel wires was determined. Numerical analysis of the process of drawing in the Drawing 2D complemented the experimental studies.

It has been shown that when drawing at high speeds, properly chosen the value of the angle of the working part of the die can improve the lubrication conditions and mechanical properties of steel wires.

Keywords: wire, drawing angle, high speed, temperature, lubrication, mechanical properties
\end{abstract}

\section{Introduction}

The drawing technology plays an important role in developing the properties of steel wires [1]. The drawing process parameters that have a significant influence on the wire properties include the angle of the die working portion [2-3]. A literature review shows that the correctly selected value of this angle ensures the carrying out of the drawing process at possibly low drawing stresses and obtaining high wire quality, and contributes to an improvement in die life [4]. Nevertheless, such studies were carried out most often using single-stage drawing machines at drawing speeds of around $1 \mathrm{~m} / \mathrm{s}$, or making use of testing machines [5]. According to Luksza [6], the optimal drawing angle value depends on many parameters, which include yield stress, friction coefficient, the sizing portion length, and single reduction values.

Currently used multi-stage drawing machines enable wires to be drawn at speeds exceeding $20 \mathrm{~m} / \mathrm{s}$. Studies [7] show that in drawing at high speeds, intensive heating of the top wire layer occurs, which leads to an impairment of lubrication conditions and wire properties. Hence, in the authors' view, an important factor in designing a multi-stage drawing process is the correct selection of the drawing angle. Establishing the optimal value of the drawing angle at high drawing speeds should improve the lubrication conditions and steel wire properties.
Based on numerical modelling and experimental tests, the effect of the die approach angle on the temperature, drawing stress, lubrication conditions and the mechanical properties of low-carbon steel wires has been determined in the study.

\section{Material and applied drawing technologies}

The starting material for the drawing process was $5.5 \mathrm{~mm}$ diameter low-carbon steel wire rod in grade $1006(0.004 \% \mathrm{C})$, which was pre-drawn into $2.2 \mathrm{~mm}$-diameter wire in seven draws. The process of drawing $2.2 \mathrm{~mm}$-diameter pre-hardened wire into $1.0 \mathrm{~mm}$-diameter wire was accomplished in 7 draws (Table 1 ) on a multi-stage drawing machine at a final speed of $25 \mathrm{~m} / \mathrm{s}$, using conventional drawing dies with drawing angles of $\alpha: 3,4,5,6,7^{\circ}$.

TABLE 1

The distribution of single reduction $G_{p}$, total reduction $G_{c}$ and drawing speed $v$

\begin{tabular}{|c|c|c|c|c|c|c|c|c|}
\hline \hline $\begin{array}{c}\text { Draft } \\
\text { number }\end{array}$ & $\mathbf{0}$ & $\mathbf{1}$ & $\mathbf{2}$ & $\mathbf{3}$ & $\mathbf{4}$ & $\mathbf{5}$ & $\mathbf{6}$ & $\mathbf{7}$ \\
\hline$\phi, \mathrm{mm}$ & 2.20 & 1.90 & 1.66 & 1.48 & 1.33 & 1.20 & 1.09 & 1.00 \\
\hline$G_{p}, \%$ & - & 25.41 & 23.67 & 20.51 & 19.24 & 18.59 & 17.49 & 15.83 \\
\hline$G_{c}, \%$ & - & 25.41 & 43.07 & 54.74 & 63.45 & 70.25 & 75.45 & 79.34 \\
\hline$v, \mathrm{~m} / \mathrm{s}$ & - & 6.93 & 9.07 & 11.41 & 14.13 & 17.36 & 21.04 & 25 \\
\hline
\end{tabular}




\section{Numerical analysis of the drawing process}

The theoretical analysis of the multi-stage high-speed drawing process was performed based on the Drawing 2D program [5], which enables the simulation of multi-stage wire drawing (with several consecutive single reductions), while considering the transfer of the strain tensor from draw to draw.

Simulation of the multi-stage drawing process was performed for pre-hardened wire with plastic properties corresponding to those of steel in grade $1006(\sim 0.04 \% \mathrm{C})$. It was assumed that the process of drawing $2.2 \mathrm{~mm}$-diameter wire into $1.0 \mathrm{~mm}$ diameter wire would be conducted in conventional dies with an angle of $\alpha=3,4,5,6,7^{\circ}$, with a friction coefficient of $\mu=0.07$. A summary of single reductions, the total reduction and drawing speed is given in Table 1 .

To determine the effect of drawing angle on the parameters of the process of multi-stage drawing fine low-carbon steel wires, the wire temperature and drawing stress were determined in the study. Figure shows sample distributions of the temperature of final $1.0 \mathrm{~mm}$-diameter wires drawn with an angle of $\alpha=6^{\circ}$, while Figure 2 illustrates the temperature on the wire surface, as dependent on the drawing angle and the total reduction.

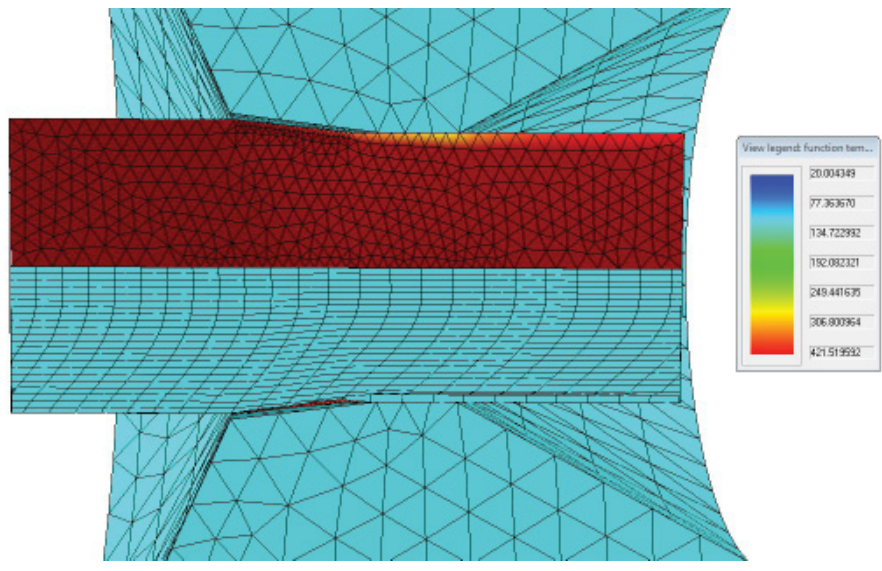

Fig. 1. The temperature distribution for final $1.0 \mathrm{~mm}$ wires drawn at die angle $\alpha=6^{\circ}$

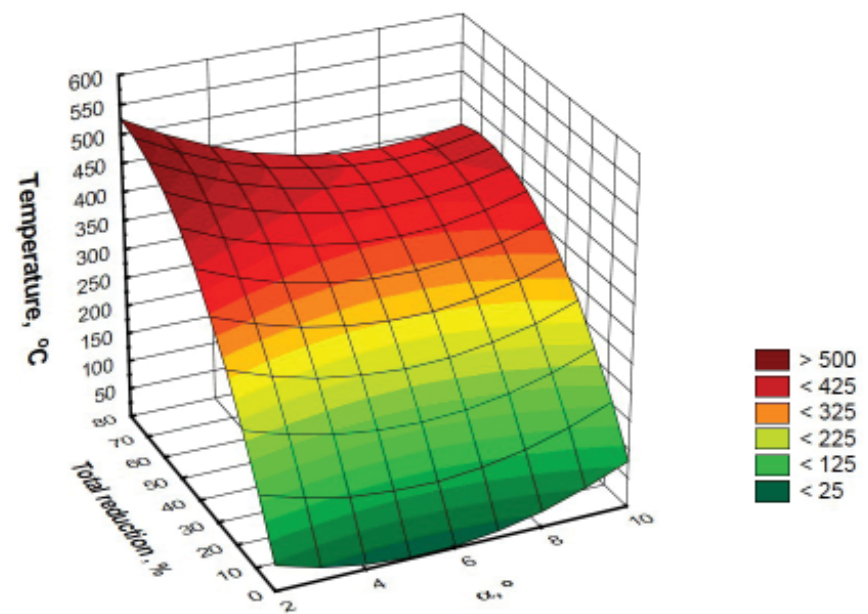

Fig. 2. The surface defining the relationship between wire surface temperature and drawing angle $\alpha$ and the total reduction
Then, the obtained results were approximated with a function of two variables, relationship (1) in the following form:

$$
\begin{aligned}
\mathrm{T}= & 108-39,3 \alpha+39,3 \alpha^{2}+ \\
& +12,3 G_{c}-0,07 G_{c}^{2}-0,3 \alpha G_{c}
\end{aligned}
$$

where: $\alpha$-drawing angle, $G_{c}$ - total reduction.

To better illustrate the effect of drawing angle on the wire temperature, based on approximating function (1), a diagram was drawn to determine the variation of wire temperature depending on the drawing angle with a total reduction of $G_{c}=80 \%$ (Fig. 3).

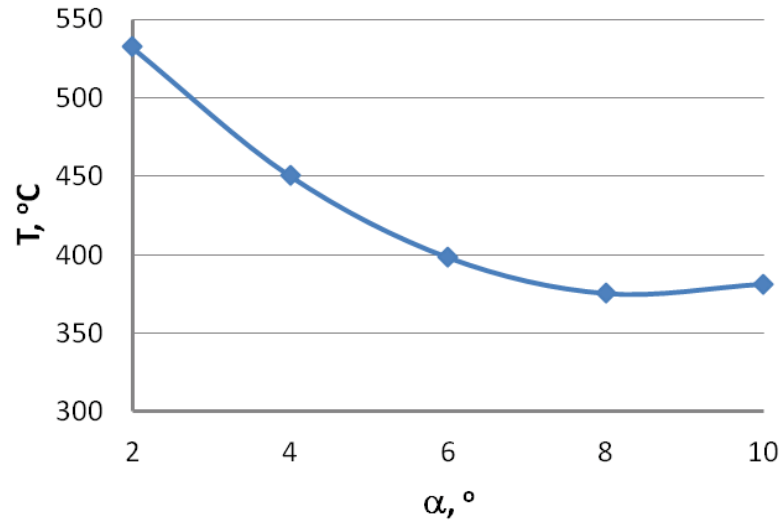

Fig. 3. Wire surface temperature as a function of drawing angle, with $G_{c}=80 \%$

The investigation carried out has confirmed definitely that, in the process of multi-stage drawing at high speeds, the angle of the working die portion significantly influences the temperature in the top wire layer. The decrease in drawing angle results in an increase in the wire and die contact length. This, in turn, leads to an increase in wire surface temperature. The differences in temperature values between wires drawn with angles of $\alpha=3^{\circ}$ and $\alpha=6^{\circ}$ amounted to about $100^{\circ} \mathrm{C}$. In the processes of drawing at high speeds, so significant temperature increase usually impairs the lubrication conditions and increases the friction, leading to additional heating of the wire. Therefore, in the authors' view, in the actual drawing process, the differences in temperature values obtained in the top wire layer are much greater. However, no significant effect of drawing angle on the average wire temperature was found, which amounted to about $75^{\circ} \mathrm{C}$ in the last draw, depending on the drawing variant.

To sum up, increasing the a angle in the high-speed wire drawing process results in a lowering of temperature in wires being drawn. On the other hand, though, it causes an increase in redundant strain and deformation non-uniformity, which may lead to an increase in drawing stress (Fig. 4).

The data represented in Fig. 4 indicates that, in the examined range $\left(\alpha=3 \div 7^{\circ}\right)$, with a constant friction coefficient, the die working portion angle does not cause any significant differences in drawing stress magnitudes. The differences varied in the range of $10 \mathrm{MPa}$. In the actual process of drawing with small values of the $\alpha$ angle, due to the increase in temperature and friction, the drawing stress is slightly higher. 


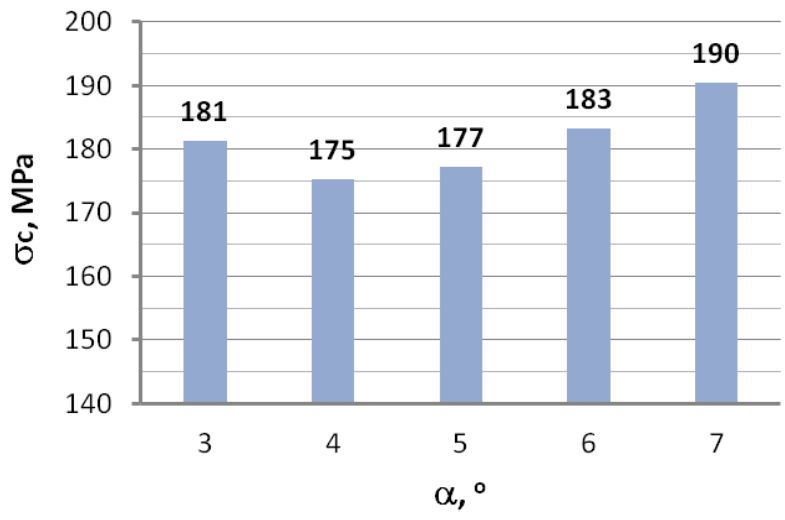

Fig. 4. The effect of the drawing angle $\alpha$ on the drawing stress $\sigma_{c}$ (the last draw)

\section{Analysis of the lubrication conditions}

The friction conditions on the wire and die contact surface are among the main factors determining the condition of the top wire layer. The selection of the appropriate die geometry in the process of drawing at high speeds should favourably influence the lubrication conditions. Hence, the quantity of lubricant on the surface of wires drawn according to individual variants has been determined in the study; the results are presented in Figs. $5 \div 6$.

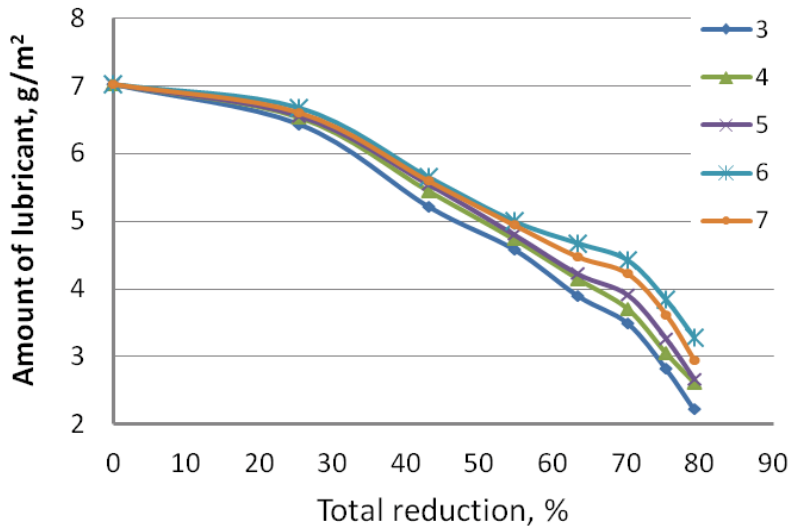

Fig. 5. The amount of lubricant on the surface of wires in total reduction function for $\alpha=3 \div 7^{\circ}$

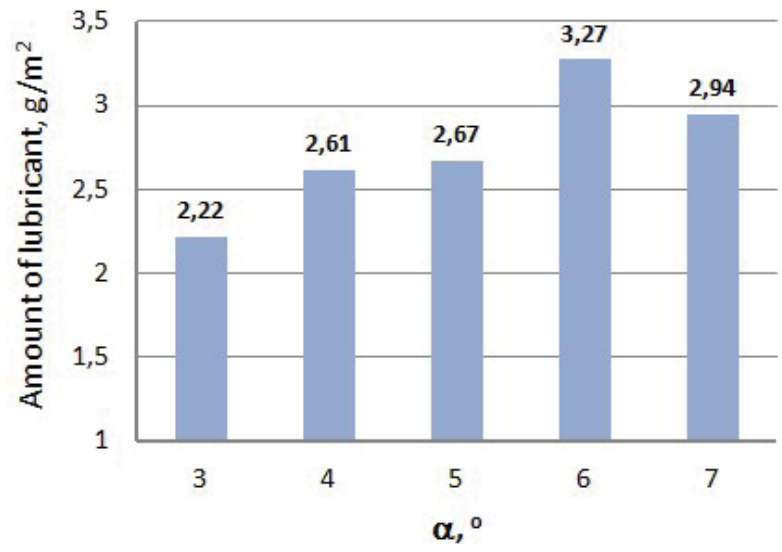

Fig. 6. The amount of lubricant on the surface of $\phi 1.00 \mathrm{~mm}$ wires in drawing angle function
The tests results shown in Figs. $5 \div 6$ demonstrate that the drawing angle significantly influences the lubrication conditions in the multi-stage drawing process. The differences between the analyzed variants increase with increasing total reduction. For wires drawn with an angle of $\alpha=6^{\circ}$, as compared to wires drawn with an angle of $\alpha=3^{\circ}$, a nearly fifty-percent increase in the quantity of lubricant was noted. The investigation has confirmed that, when drawing fine wires of low-carbon the angle $\alpha=6^{\circ}$ enables the largest quantity of lubricant to be obtained on the wire surface. The significant decrease in the quantity of lubricant on wires drawn with small angles should be linked with the occurrence of a larger friction surface at the wire and die contact. This caused an increase in wire temperature and, as a consequence, an impairment of lubrication conditions.

\section{Analysis of mechanical properties}

Tests for the mechanical properties of wires were carried out in accordance with standard PN-EN 10218-1:2012, where the yield strength, YS, the tensile strength, TS, the reduction of area, RA, and the uniform elongation, UEl, are specified. The test results are given in Table 2 and shown in Figures $7 \div 11$.

TABLE 2

Mechanical and engineering properties of wire rod and $2.2 \mathrm{~mm}$-diameter wire

\begin{tabular}{|c|c|c|c|c|}
\hline \hline $\boldsymbol{\phi}, \mathbf{m m}$ & YS, MPa & UTS, MPa & RA, \% & UEL, $\%$ \\
\hline 5.5 & 272.2 & 361.1 & 77.6 & 28.8 \\
\hline 2.2 & 511.1 & 774.5 & 55.3 & 2.21 \\
\hline
\end{tabular}

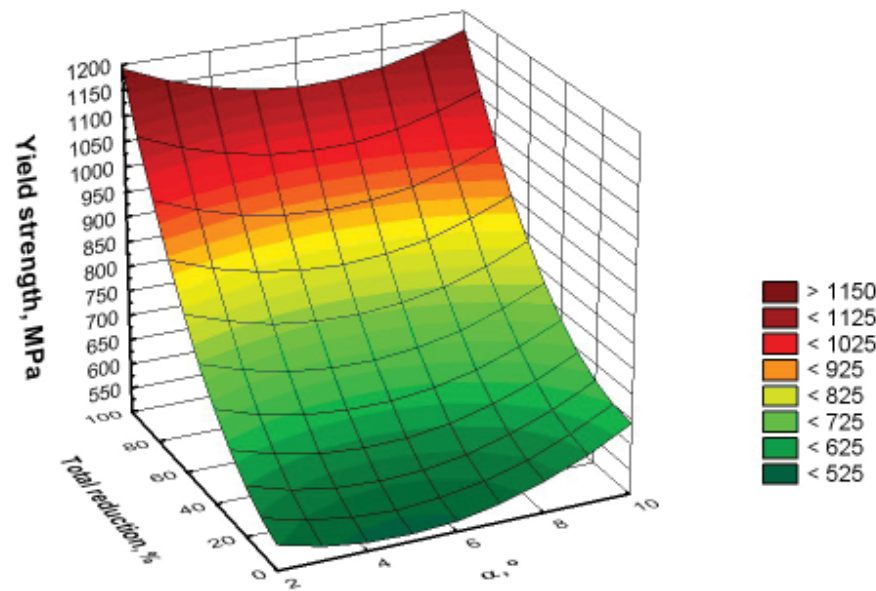

Fig. 7. The surface defining the relationship between the yield strength and drawing angle $\alpha$ and the total reduction

Then, the obtained results were approximated with a function of two variables, relationship (2) in the following form:

$$
\begin{aligned}
\mathrm{TS}= & 887,2-47,1 \alpha+4,8 \alpha^{2}+ \\
& +2,2 G_{c}+0,03 G_{c}{ }^{2}-0,15 \alpha G_{c}
\end{aligned}
$$

where: $\alpha$-drawing angle, $G_{c}$ - total reduction. 


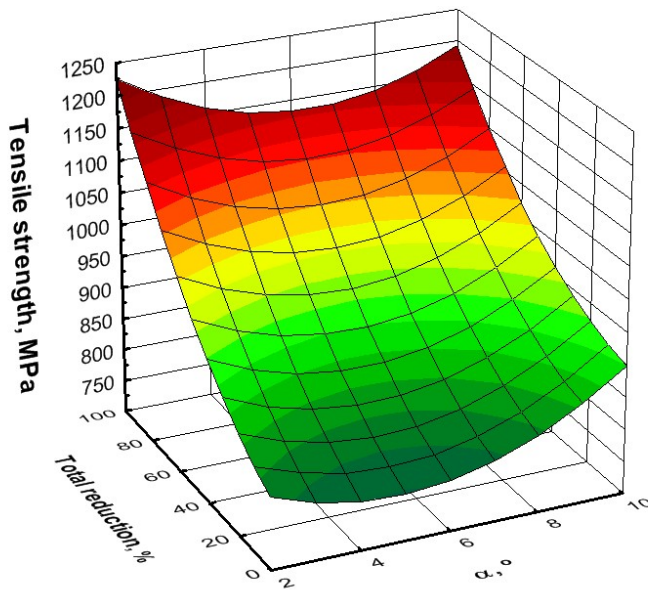

Fig. 8. The surface defining the relationship between the tensile strength and drawing angle $\alpha$ and the total reduction

To better illustrate the effect of drawing angle on the mechanical properties of wires, based on approximating function (2), a diagram was drawn to determine the variation of tensile strength depending on the drawing angle, with a total reduction of $G_{c}=80 \%$ (Fig. 9).

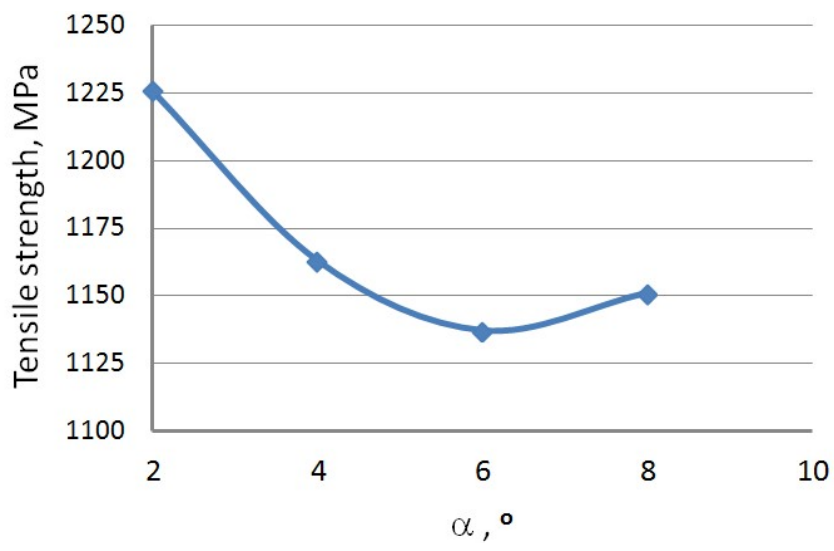

Fig. 9. The tensile strength of $1.0 \mathrm{~mm}$-diameter wires as a function of drawing angle, with $G_{c}=80 \%$

From on the results shown in Fig. 2 it can be found that the drawing angle influences the mechanical properties of lowcarbon steel wires, whereby the smaller the drawing angle, the higher the yield strength and tensile strength values. Using the angle $\alpha=3^{\circ}$ in the high-speed drawing process resulted in an increase in the mechanical properties of wires by approx. $7 \%$. As a consequence, the wires from the analyzed drawing variant should be distinguished by lower plastic properties, as confirmed by the data represented in Figs. 10 $\div 11$.

From the plasticity tests of low-carbon steel wires (Fig. 3) it has been demonstrated that drawing angle magnitudes influence the plastic properties of wires. The differences in the values of uniform elongation and the reduction of area increase with increasing total reduction, and at a total reduction of $G_{c}=80 \%$ they amount to approx. $8 \%$. The best plastic properties were obtained for wires drawn with an angle of $\alpha=6^{\circ}$. Either decreasing

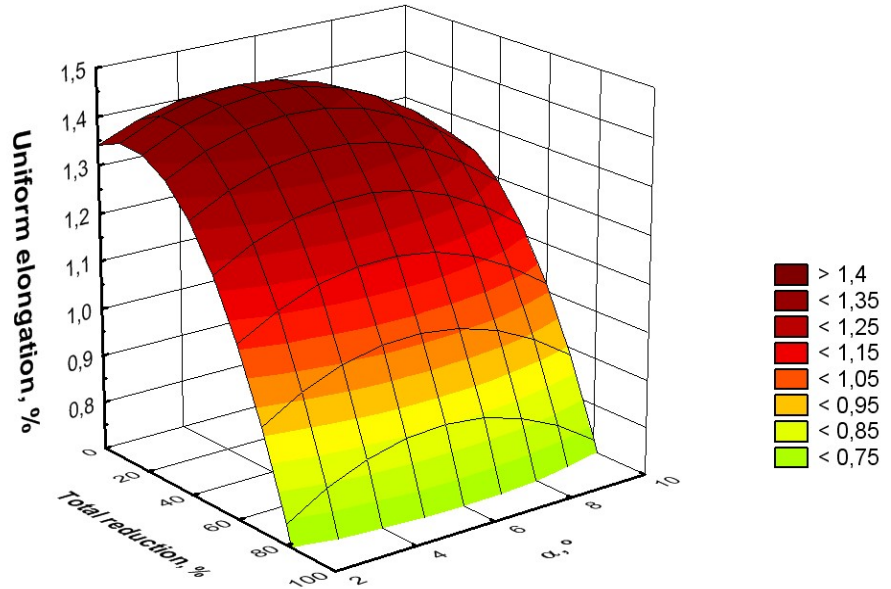

Fig. 10. The surface defining the relationship between the uniform elongation and drawing angle $\alpha$ and the total reduction

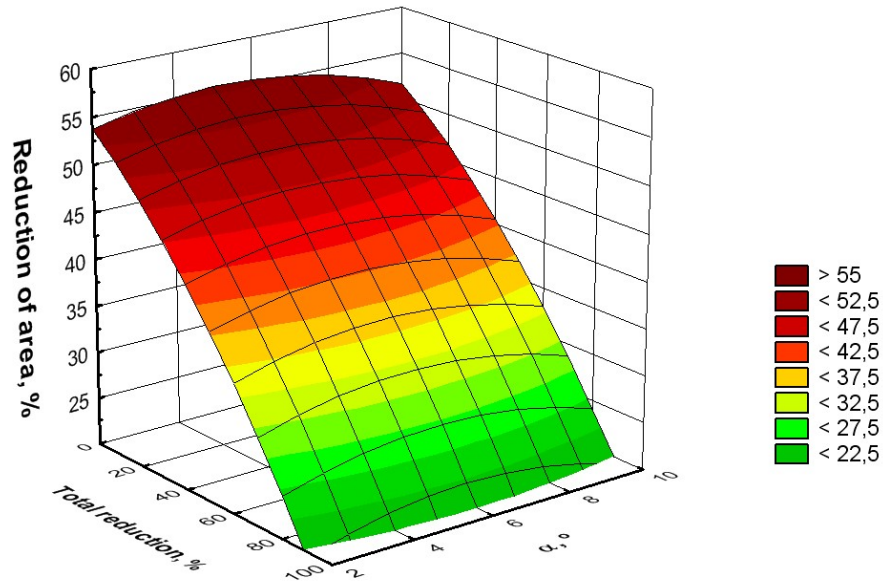

Fig. 11. The surface defining the relationship between the reduction of area and drawing angle $\alpha$ and the total reduction

or increasing the value of the die working portion angle results in gradual decreasing of the plastic properties, which should be linked with lubrication conditions that are poorer for these variants and with the increase in hardening.

In the authors' view, the several-percent differences in the obtained results for mechanical properties should be associated with the too low carbon content of the steel $(0.04 \% \mathrm{C})$. It can be expected that in drawing wires of medium- and high-carbon steels exhibiting a much larger percentage fraction of pearlite of the structure, the drawing angle influences the degree of fragmentation of hard cementite lamellas, structure orientation and top layer hardening to a greater extent.

The investigation has shown that the analysis of the drawing angle is a complex issue, because two opposing phenomena exist in the drawing process. On the one hand, increasing the a angle in the drawing process causes an increase in redundant strain and strain non-uniformity, while, on the other hand, results in a decrease in drawn wire temperature. The ultimate result of drawing angle influence depends on which phenomenon prevails. The investigations reported in works [1] show that in multi-stage drawing at high speeds, the wire surface undergoes intensive 
heating up to temperatures, at which the thermal decomposition of the lubricant occurs. This, in turn, leads to a drop in the amount of lubricant on the wires and an increase in friction on the wire and die friction surfaces. The investigations reported in the paper have confirmed that a determining factor in the process of high-speed multi-stage drawing low-carbon steel wires is the length of the wire and die contact. Too small values of the die working portion angle cause an over 20-percent increase of temperature in the top wire layer. Hence, for wires drawn with an angle of $\alpha=3^{\circ}$, as compared with wires drawn with an angle of $\alpha=6^{\circ}$, a decrease in the amount of lubricant by nearly $50 \%$ was noted. The decrease in the amount of lubricant between the wire and die friction surfaces contributed to an increase in mechanical properties and an impairment of plastic properties by, respectively, 7 and $8 \%$.

\section{Conclusions}

1. In the high-speed drawing process, a factor that determines the optimal value of the drawing angle is the length of the wire and die contact surface. Too small values of the die working portion angle cause added intensive heating of the top wire layer.

2. The drawing angle significantly influences the lubrication conditions in the process of high-speed multi-stage drawing low-carbon steel wires. Depending on the adopted drawing angle, the differences in the quantity of lubricant on the wire surface amount to almost $50 \%$.

3. It has been demonstrated that the best conditions of drawing thin wires are ensured by the angle $\alpha=6^{\circ}$. Using too small drawing angles in the low-carbon steel wire drawing process causes an increase in wire temperature, an impairment of lubrication conditions, a decrease in plastic properties and an increase in their mechanical properties.

4. Establishing the optimal drawing angle value in high-speed multi-stage drawing should enable the improvement of the lubrication conditions and steel wire properties.

\section{REFERENCES}

[1] M. Suliga, Analysis of the multipass steel wire drawing with high speed in conventional and hydrodynamic dies (Analiza wielostopniowego ciagnienia drutów stalowych z dużymi prędkościami w ciagadłach konwencjonalnych i hydrodynamicznych - in Polish), monograph No. 32. Czestochowa University of Technology, Publishing House of the Faculty of Process and Materials Engineering and Applied Physics: Czestochowa (2013).

[2] J.G. Wistreich, The Fundamentals of wire drawing. Metallurgical Reviews 3, 10, 97-141 (1958).

[3] J. Łuksza, J. Majta, Odkształcenia zbędne w prętach i drutach ciągnionych, Hutnik 4, 134-137 (1989).

[4] F. Knap, R. Karuzel, Ł. Cieślak, Ciagnnienie drutów, prętów i rur, Metalurgia Nr 36, Wyd. Wydz. Inżynierii Procesowej, Materiałowej i Fizyki Stosowanej Politechniki Częstochowskiej, Częstochowa (2004).

[5] F. Knap, L. Latacz-Pilarczyk, J. Pilarczyk, Badanie wpływu kąta stożka zgniatającego ciągadła na własności mechaniczne drutu do konstrukcji sprężonych, Zeszyty Naukowe Politechniki Częstochowskiej 89, 9, 21-34 (1974).

[6] J. Łuksza, Elementy ciagarstwa, AGH, Kraków (2001).

[7] M. Suliga, Analysis of the heating of steel wires during high speed multipass drawing process. Archives of Metallurgy and Materials 59, 4, 1475-1480 (2014). 